\title{
Understanding the pressures of coaching: insights of young UK coaches working with elite junior tennis players
}

\author{
Callum Gowling ${ }^{\text {a }}$ \\ ${ }^{a}$ Liquid Sport Psychology, United Kingdom.
}

\begin{abstract}
Despite a growing body of research into sports coaching there remains little understanding of what it is like to coach elite junior tennis players. The purpose of this study was to examine the lived coaching experience of $8 \mathrm{UK}$, less experienced tennis coaches and describe what it is like to be a coach of an elite junior tennis player. An Interpretative Phenomenological Analysis (IPA) of 8 less experienced tennis coaches (1 4 years-experience) provides a description of how they described elite junior tennis coaching. This study found that (a) self-employment makes coaching competitive, (b) less experienced coaches were surprised by the nature of parental interactions, and (c) less experienced coaches struggled to cope with the reality of coaching and this triggered disillusionment with coaching. The findings of this research contribute to an evolving, problematic epistemology of sports coaching and highlight a need for tennis coach education to improve the preparation of new coaches for their initiation into coaching. The findings present governing bodies opportunities to inform coach education literature and help tennis coaches to sustain themselves in an emotionally challenging role.
\end{abstract}

\author{
Key words: Interpretative \\ Phenomenological Analysis, \\ coaching, elite players, \\ attitudes. \\ Received: 30 May 2019 \\ Accepted: 02 September 2019 \\ Corresponding author: Callum \\ Gowling, Liquid Sport \\ Psychology, United Kingdom. \\ Email: \\ callumgowling@btinternet.com
}

\section{INTRODUCTION}

So, what is it like to be a tennis coach? Working outdoors in the sun, getting regular exercise, earning a living by helping others, and keeping your hand in at the sport you've always loved - tennis coaching is a great career. However, like other helping professions (e.g. teachers, nurses, doctors) tennis coaches face challenges that can affect their personal lives, professional relationships, job motivation and mental wellbeing.

Tennis coaches are performers in their own right as they are required to manage the development and the performance of their athletes through communication, presentation, and psychological skills (Kelly et al., 2018). To be effective, coaches must maintain their mental well-being, so they can observe and respond to the unique characteristics of their athletes. Issues that affect the mental well-being of tennis coaches can change their coaching delivery, their motivation, the relationship with their athlete, and their self-esteem. Furthermore, prolonged periods of stress lead to coach burnout, where coaches stop enjoying coaching and leave the profession (Lundkvist et al., 2012).
This article looks at the experiences of UK tennis coaches, with less than 4 years coaching experience and shows some of the issues that they find challenging. For example, tennis coaching is competitive because many UK tennis coaches are self-employed. The self-employed nature of tennis coaching makes developing positive professional relationships difficult because of the coaches' need to sustain their self-employed income. Understanding the challenges that tennis coaches face and the affect such challenges have on their attitudes can help educators and governing bodies prepare new coaches for what lies ahead of them. This report highlights that young tennis coaches find their role competitive and challenging because of regular conflicts with parents. The evidence suggests that coaches with less than 4 years-experience struggle to cope with competition and conflict in coaching and this has triggered disillusionment with coaching. 


\section{METHOD}

This study was an interpretative phenomenological analysis (IPA) of 8 less experienced tennis coaches who worked with elite junior tennis players in the UK. The participants included 7 males and 1 female and were aged between 23 and 36 years. The participants worked in the following areas; Scotland (1), Northern England (3), Midlands (1), Southern England (2), and Wales (1). The less experienced coaches had $1-4$ years coaching experience with elite juniors (Flett et al., 2012). Participants were currently working with elite junior tennis players and held level 4 or 5 LTA coaching qualifications. Junior tennis players were aged between 11 - 18 years old, corresponding with the LTA yellow ball competition system. Junior elite was defined as competing at national level competition and above (Rees et al., 2016). The interviews in this study were semi-structured and the aim was to understand what it was like for participants to coach elite junior tennis players. Interviews lasted between 1.5 and 3.5 hours and were audio recorded. Interviews were transcribed verbatim, printed out, and analysed by following the procedure for IPA.

\section{RESULTS}

The results show that: (a) self-employment makes coaching competitive; (b) less experienced coaches were surprised by the nature of parental interactions; and, (c) less experienced coaches struggled to cope with the reality of coaching and this triggered disillusionment with coaching.

\section{Self-employment makes coaching competitive}

The participants found the coaching environment challenging and they described self-employment as an issue that made coaching competitive. Self-employment gave coaches the freedom to work with whomever they wanted and pick the times they worked but also created difficulties with how they interacted with other coaches. Amy described selfemployment making coaches competitive:

"A lot of coaches are self-employed, if they were employed then maybe they'd be on the same page more. It's full of ego and one-up-man-ship because they are self-employed... That's how ego and things get out of control, because you are worried about yourself and your income."

Competition between coaches was a consistent theme and self-employment appeared to drive much of this competitiveness. Phil said: "I think they (coaches) feel that instead of having the kids interests at heart, the whole thing can become a competition (between coaches). Everyone is fighting for business".

One could assume that being self-employed requires individuals to view others as competition. Participants were struggling to cope with the nature of self-employment and balance this with seeking help from other coaches. Peter said: "I'd love to be able to go to another centre and talk about my players. But if they (another coach) gave me a solution that worked then they'd want the credit, or they'd want my player". Self-employment meant the participants saw other coaches as rivals.

Supporting a cohesive coaching community was challenging for the participants because other coaches were threats to their income. Nathan said "you can't talk to other coaches about your issues because you lose face. They (other coaches) are your competition, aren't they?" Self-employment continued to influence the participants behaviours towards other coaches and created untrusting attitudes towards other coaches.

Less experienced coaches were surprised by the nature of parental interactions

There was evidence to suggest that the participants were surprised by the nature of their interactions with parents of the players they taught. When discussing parental interactions participants regularly described conflict. For example, Josh said: "Do parents feel less inclined to criticise older coaches, because they are older than the parents, or because they're a national coach and they want something from them? I want to say, 'who the hell do you think you are' to these parents".

Unsurprisingly, parents are an important part of tennis coaches' realities because they are the ones that bring their children to training. The participants consistently expressed surprise at the nature of interactions with parents. Nathan said: "Why do parents get so much of a voice in tennis, because in other sports they don't? Tennis is the sport that parents feel like they can just say l'm not happy with you". The lack of experience that the participants had with parent interactions could mean that they were uncomfortable with such interactions and that these experiences cause the coaches uncertainty.

Participants described parent's attitudes as extremes on a continuum, either very positive or very negative. Josh said "when a player wins, the parents are really happy. When a player loses, my coaching is rubbish". Participants continuously described parents as difficult to satisfy or wanting instant results and this created uncertainty for participants as they did not feel able to sustain positive results and keep parents happy.

Less experienced coaches struggled to cope with the reality of coaching which can lead to disillusionment with coaching

The participants were uncomfortable with the coaching environment and there were signs early in their careers that they were questioning their involvement. For example, Josh said: "I really can't see myself doing it (coaching) past 30-35. I might have gone mad by then! Hopefully I produce a player and go on tour with them and leave these parents and this moaning behind".

The primary concern for the participants remained competition and parental conflict. With less than 4 years 
coaching experience in the elite context, the participants seemed ill equipped to cope effectively with their experiences. Nathan said: The tennis coaching world is a funny one. Everyone (parents and coaches) hates each other! So much aggro and people hawking (stealing) players off each other. Bitching parents, backstabbing coaches. Jesus it's hard work".

The challenges of tennis coaching were having a negative effect on the participants job satisfaction and this resulted in them questioning whether they wanted to continue as coaches. Phil said: "It's not as good a job as when you first go into it, I think. That's the worrying thing. How many coaches are there like me saying the same thing? I don't like it (coaching) anymore. There must be loads (of coaches saying this)".

Coping strategies are an important factor in all professionals' working lives so they can sustain their mental state in the face of challenges. Coping Strategies take time to develop (Thelwell et al., 2010; Kelly et al., 2018) and the participants in this study were struggling to cope effectively with their challenges, causing issues with job satisfaction and motivation to coach.

\section{DISCUSSION}

The data in this study highlights several issues that less experienced tennis coaches face in their day-to-day activities.

Firstly, this study highlighted self-employment as a significant factor in participants' opinions of other tennis coaches and was associated with distrusting of other coaches. Participants described negative attitudes towards other coaches, and this was generally associated with self-employment. Participants feared having less favourable reputations than other coaches because it could directly affect their income (Cassidy et al., 2016).

Secondly, participants described intolerant attitudes towards parental involvement in elite tennis. Parent interactions are a coaching stressor (Knight \& Harwood, 2009) and this study shows untrusting attitudes towards parents. Participants described avoidance of parent interaction and highlighted discomfort with parental involvement.

Thirdly, the participants were insecure about their coaching experiences and described demotivation when they were unable to cope with their experiences. Less experienced coaches described inner-conflicts with job satisfaction, and this had a negative effect on their motivation to remain as tennis coaches (Kelchtermans; 2009a; 2009b).

\section{CONCLUSION}

The findings suggest that less experienced coaches require emotional support early in their coaching careers. Bandura said, "It is difficult to achieve much while fighting self-doubt" (1997, p. 118) and there was evidence throughout this study that participants were doubting themselves. The findings support assertions that coach education could use insights of experienced coaches more effectively to prepare new practitioners for their roles (Cushion, Jones \& Armour, 2003). Participants were anxious about challenges that they faced in their day-to-day activities, and their anxieties had a negative effect on their motivation to coach (Bleach, 2019).

Educating new coaches about the coping mechanisms used by experienced practitioners would help to: (a) raise awareness that coaches will experience emotional challenges in their careers; and, (b) enable new coaches to select coping strategies that have worked for other coaches.

\section{REFERENCES}

Bandura, A. (1997). Self-efficacy: The exercise of control. New York: Freeman \& Company.

Bleach, C., (2019). Fragile Learning: The Influence of Anxiety, Psychodynamic Practice, 25:1, 86-90, DOI: 10.1080/14753634.2018.1499038, https://doi.org/10.1080/14753634.2018.1499038

Cassidy, T. Jones, R. \& Potrac, P. (2016). Understanding Sports Coaching: The pedagogical, social and cultural foundations of coaching practice. Third edition. New York: Routledge, https://doi.org/10.4324/9780203797952

Cushion, C.J., Armour, K.M. \& Jones, R.L., (2003). Coach Education and Continuing Professional Development: Experience and Learning to Coach, Quest, 55, 215-230, https://doi.org/10.1080/00336297.2003.10491800

Flett, R. Gould, R. Griffes, K. \& Lauer, L. (2012). The views of more versus less experienced coaches in undeserved communities. International Journal of Coaching Science, Vol 6 (1), pp 3 - 26.

Kelchtermans, G. (2009a). Who I am in how I teach the message: Self-understanding, vulnerability, and reflection? Teachers and Teaching: Theory and Practice, 15(2):257-272, https://doi.org/10.1080/13540600902875332

Kelchtermans G. (2009b) Career Stories as Gateway to Understanding Teacher Development. In: Bayer M., Brinkkjær U., Plauborg H., Rolls S. (eds) Teachers' Career Trajectories and Work Lives. Professional Learning and Development in Schools and Higher Education, vol 3. Dordrecht: Springer

Kelly, S. Thelwell, R. Barker, J. B. \& Harwood, C. G. (2018). Psychological support for sport coaches: an exploration of practitioner psychologist perspectives, Journal of Sports Sciences, 36:16, 1852-1859, DOI: 10.1080/02640414.2018.1423854, https://doi.org/10.1080/02640414.2018.1423854

Knight, C. J. \& Harwood, C. G. (2009). Exploring ParentRelated Coaching Stressors in British Tennis: A Developmental Investigation, International Journal of Sports Science \& Coaching Volume 4, Number 4, p 545 565, https://doi.org/10.1260/174795409790291448

Lundkvist, E. Gustafsson, H. Hjälm, S. \& Hassmén, P. (2012). An interpretative phenomenological analysis of burnout and recovery in elite soccer coaches, Qualitative Research in Sport, Exercise and Health, 4:3, 400-419, DOI: 
10.1080/2159676X.2012.693526,

https://doi.org/10.1080/2159676X.2012.693526

Rees, T. Hardy, L. Gullich, A. Abernethy, B. Cote, J. Woodman, T. Montgomery, H., Laing, S. \& Warr, C. (2016). The Great British Medalists Project: A Review of Current Knowledge on the Development of the World's Best Sporting Talent. Sports Med, Vol 46, pp 1041 - 1058,

https://doi.org/10.1007/s40279-016-0476-2

Thelwell, R. C., Weston, N. J., \& Greenlees, I. A. (2010). Coping with stressors in elite sport: A coach perspective. European Journal of Sport Science,10, 243e253, https://doi.org/10.1080/17461390903353390

RECOMMENDED ITF TENNIS ACADEMY CONTENT (CLICK BELOW)

\section{ITF Academy}

Copyright (c) 2019 Callum Gowling

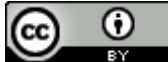

This text is under a Creative Commons BY 4.0 license

You are free to Share - copy and redistribute the material in any medium or format - and Adapt the content - remix, transform, and build upon the material for any purpose, even commercially under the following terms:

Attribution: You must give appropriate credit, provide a link to the license, and indicate if changes were made. You may do so in any reasonable manner, but not in any way that suggests the licensor endorses you or your use.

CCBY4.0 license terms summary CCBY4.0license terms 